\title{
Microglial Response to Gold Nanoparticles
}

\author{
Eliza Hutter, ${ }^{t, \neq}$ Sebastien Boridy, ${ }^{\dagger}$ Simon Labrecque, ${ }^{\S}$ Melanie Lalancette-Hébert, ${ }^{\S}$ Jasna Kriz, ${ }^{\S}$ \\ Françoise M. Winnik, ${ }^{*}$ and Dusica Maysinger ${ }^{\dagger, *}$ \\ 'Department of Pharmacology \& Therapeutics, McGill University, McIntyre Medical Sciences Building, Montreal, QC H3G 1Y6, Canada, ,Department of Chemistry, Faculty \\ of Pharmacy, University of Montreal, Pavilion J.A. Bombardier, Montreal, QC H3C 3J7, Canada, ${ }^{\S}$ Department of Cellular Neurobiology, Centre de Recherche Université \\ Laval Robert-Giffard, Quebec, QC G1J 2G3, Canada, and §Department of Anatomy and Physiology, Laval University, Centre de Recherche du Centre Hospitalier de \\ I'Université Laval, Quebec, QC G1 V 4G2, Canada
}

G old nanoparticles (GNPs) have become highly valuable tools in biological sciences, mainly because of their biocompatibility, facile conjugation to biomolecules, and tunable optical properties depending on their size, surface layer, and shape. During the past few years, GNPs have demonstrated applicability in imaging, ${ }^{1}$ sensing, ${ }^{2-4}$ drug and gene delivery, ${ }^{5,6}$ and in photothermal therapy. ${ }^{\text {? }}$

Most applications take advantage of the unique optical properties of GNPs supported by their localized surface plasmon resonance (LSPR). ${ }^{8,9}$ The excitation of localized surface plasmons that occurs for a specific frequency of light results in strong light scattering, intense absorption, and enhancement of electromagnetic fields. Exploiting these properties, in situ imaging of GNPs is most commonly performed by resonant light scattering, ${ }^{10}$ dark-field microscopy, ${ }^{11}$ and, more recently, by two-photon luminescence microscopy..$^{12,13}$ Spheres $^{14}$ are among the best characterized GNPs and have been widely exploited for their fundamental imaging capabilities. However, their use in vivo is limited by the fact that their absorption occurs in the visible spectral region, which can cause photochemical damage and also precludes in vivo applications necessitating penetration of light into deep tissues. ${ }^{15}$ Over the past few years, a great variety of novel nanosized gold objects have been prepared, such as rods, ${ }^{16,17}$ urchins, ${ }^{18-20}$ prisms, ${ }^{21}$ wires, ${ }^{22}$ disks, ${ }^{23}$ and stars, ${ }^{24,25}$ which display varying optical properties based on their size, shape, and surface chemistry. Many of these, including rods and urchins, have optical resonances in the near-infrared spectral window, which penetrates deeply within tissues and does not cause photochemical damage. In par-

www.acsnano.org

ABSTRACT Given the emergence of nanotherapeutics and nanodiagnostics as key tools in today's medicine, it has become of critical importance to define precisely the interactions of nanomaterials with biological systems and to characterize the resulting cellular response. We report here the interactions of microglia and neurons with gold nanoparticles (GNPs) of three morphologies, spheres, rods, and urchins, coated with poly(ethylene glycol) (PEG) or cetyl trimethylammonium bromide (CTAB). Microglia are the resident immune cells of the brain, primarily involved in surveillance, macrophagy, and production of cytokines and trophic factors. Analysis by dark-field microscopy and by two-photon-induced luminescence (TPL) indicates that the exposure of neural cells to GNPs resulted in (i) GNP internalization by both microglial cells and primary hippocampal neurons, as revealed by darkfield microscopy and by two-photon-induced luminescence (TPL), (ii) transient toll-like receptor 2 (TLR-2) upregulation in the olfactory bulb, after intranasal administration in transgenic mice, in vivo, in real time, and (iii) differential up-regulation in vitro of TLR-2 together with interleukin 1 alpha (IL-1 $\alpha)$, granulocyte macrophage colony-stimulating factor (GM-CSF) and nitric oxide (NO) in microglia. The study demonstrates that GNP morphology and surface chemistry strongly influence the microglial activation status and suggests that interactions between GNPs and microglia can be differentially regulated by tuning GNP nanogeometry.

KEYWORDS: nanourchins - gold nanorods - two-photon luminescence imaging (TPL) - microglial activation · toll-like receptor $\cdot$ cytokines

ticular, urchin GNPs, or nanourchins, have unique surface geometry, consisting of numerous "bumps" and "thorns", which enhance the localized electromagnetic field making gold nanourchins particularly valuable for imaging applications. ${ }^{26}$ Nonetheless, in spite of these enabling optical characteristics, gold nanourchins have not been used for intracellular or in vivo imaging applications.

Given the potential applications of GNPs in therapeutics and diagnostics, characterizing their interactions with the cellular milieu is essential. Most recent reports have focused on the importance of size in defining the interaction of GNPs with cells in terms of cellular uptake, ${ }^{27-29}$ organ distribution, ${ }^{30,31}$ and cytotoxicity. ${ }^{32,33}$ Modification of the GNP surface with cell-penetrating peptides ${ }^{13}$ and receptor-specific antibodies ${ }^{34}$ has
See the accompanying Perspective by Albanese et al. on p 2490.

*Address correspondence to dusica.maysinger@mail.mcgill.ca.

Received for review December 21, 2009 and accepted March 15, 2010.

Published online March 23, 2010. $10.1021 / \mathrm{nn} 901869 f$

() 2010 American Chemical Society 


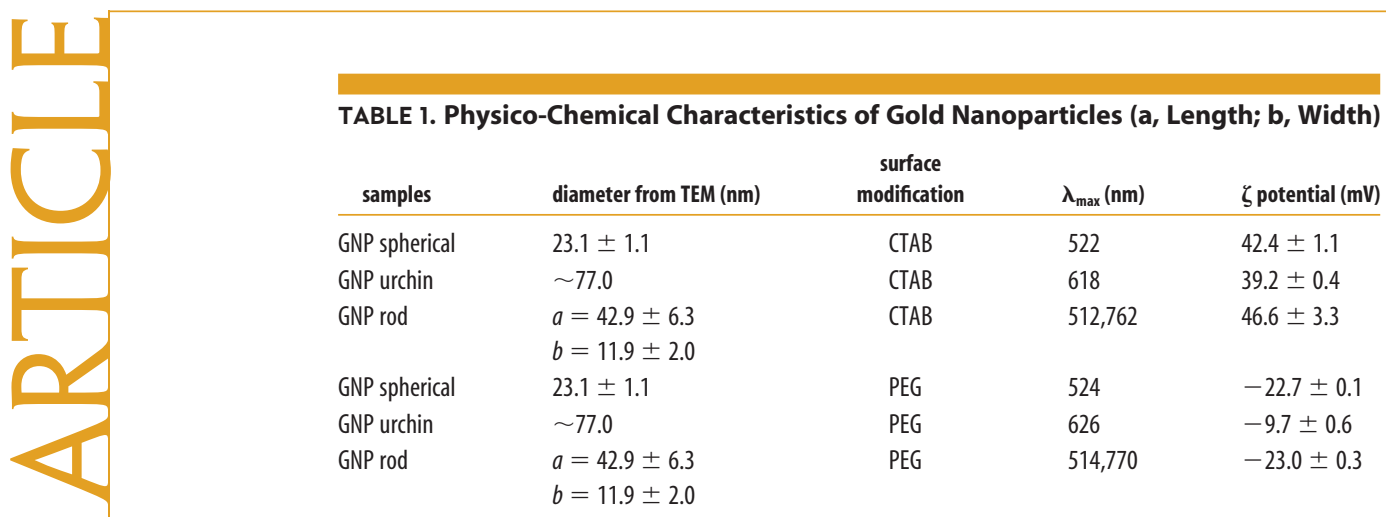

tinct shapes, and, consequently, with different optical characteristics (i.e., spheres, rods, and urchins). The GNPs cytotoxic effects were assessed using a neural cell line, and the uptake of GNPs was evaluated and compared in primary neuronal cells and microglial cells. Furthermore, the response to GNPs in live animals was evaluated in real

also been used to control cellular uptake. Huff and colleagues have shown that surface conjugation with poly(ethylene glycol) and cetyltrimethylammonium bromide can directly inhibit or promote, respectively, the internalization of gold nanorods. ${ }^{35}$ Most importantly, it has become apparent that the nanomaterial shape plays a significant role in cell interactions. ${ }^{36,37}$ Chan's group has shown that spheres, in particular $50 \mathrm{~nm}$ sized GNPs, are taken up to a significantly greater extent than rods, independently of their aspect ratio. ${ }^{28,29}$ This observation has been confirmed by other studies. ${ }^{38}$ So far, only two shapes (spheres vs rods) have been compared in terms of internalization. Moreover, the effect of GNP shape on cellular response, beyond uptake, has not been evaluated at all, although this factor is critical for in vivo applications.

The use of GNPs as imaging agents could provide a promising future for high contrast imaging within the central nervous system (CNS) in pathologies, such as Alzheimer's disease, that presently lack early and accurate diagnostic tools. However, there is only limited data on the interactions of GNPs with cells of the CNS. Microglial cells, which are regarded as the main immune effectors of the brain, are particularly highly responsive under pathological conditions (e.g., inflammation), ${ }^{39}$ where they exhibit higher expression of activation markers, such as pattern recognition receptors (PRRs) required for early detection and clearance of pathogens. Toll-like receptors (TLRs) constitute one of the four major classes of PRRs found on the surface of microglial cells. They are regulated both upstream and downstream by the transcription nuclear factor $\kappa$ enhancer binding protein (NFkB). ${ }^{40}$ Activation of microglia, as dictated by the expression of PRRs and release of pro-inflammatory signals (i.e., cytokines), can markedly affect brain functions. ${ }^{41}$ Thus, studying the response of microglia to nanomaterials is of considerable importance in the development of nanotherapeutics and nanodiagnostics.

The long-term objective of our studies is to develop high contrast optical tools enabling in vivo realtime imaging of the brain without causing long-lasting and irreversible damage to the nervous system. To this end, we prepared and characterized GNPs of three dis- time using a transgenic mouse expressing luciferase controlled by the microglia-specific promoter driven by the toll-like receptor-2 (TLR-2), a marker of microglial activation. The signaling mechanisms that govern GNP-mediated microglial responses were investigated in vitro. Presently, knowledge with regard to the response of the central nervous system to GNPs is very limited. In pathological states of the CNS, when diagnosis and treatment are quite challenging, GNPs with targeting ligands conjugated to their surface may serve as a suitable therapeutic and diagnostic tool.

\section{RESULTS AND DISCUSSION}

Characterization of Gold Nanoparticles. Sphere, rod, and urchin GNPs were prepared by in situ formation of gold upon reduction of gold chloride in the presence of suitable reagents and seeds, as required to induce the desired morphology. Since the focus of the study is the impact of GNP morphology and not that of their interfacial properties, it was important to have the same stabilizing surface molecules for all shapes. We chose to PEGylate all GNPs prepared, in view of the well-established safety and low (and in some cases, no) immunogenic characteristics of tethered poly(ethylene glycol) chains. ${ }^{42}$ PEG modification is a common approach to achieve biocompatibility. It reduces nonspecific binding of biomolecules to surfaces, but it also decreases cellular uptake. ${ }^{42}$ For twophoton luminescence studies, we wished to ensure a high level of internalization, and therefore, for these experiments, we have prepared and used all three GNP shapes (spheres, rods, and urchins) with the cationic surfactant $C T A B$ on their surface.

The physical characteristics of the GNPs synthesized are listed in Table 1. The spherical GNPs as prepared $(d=23.1 \pm 1.1 \mathrm{~nm}$, Figure $1 \mathrm{~A})$ in water exhibited a plasmon band with a maximum wavelength at $522 \mathrm{~nm}$ (Figure 1a). This band broadened and shifted to a slightly longer wavelength ( $\lambda_{\max }=524 \mathrm{~nm}$ ) upon PEGylation of the particles. The ligand exchange was further confirmed by a shift of $\zeta$ potential from $+42.4 \pm 1.1$ to $-22.7 \pm 0.1 \mathrm{mV}$. The irregularly shaped urchin GNPs were estimated to have an average volume equal to that of a sphere $77 \mathrm{~nm}$ in diameter. The extinction band recorded for urchin GNPs in water had a maximum wavelength of $618 \mathrm{~nm}$, a value significantly red-shifted 

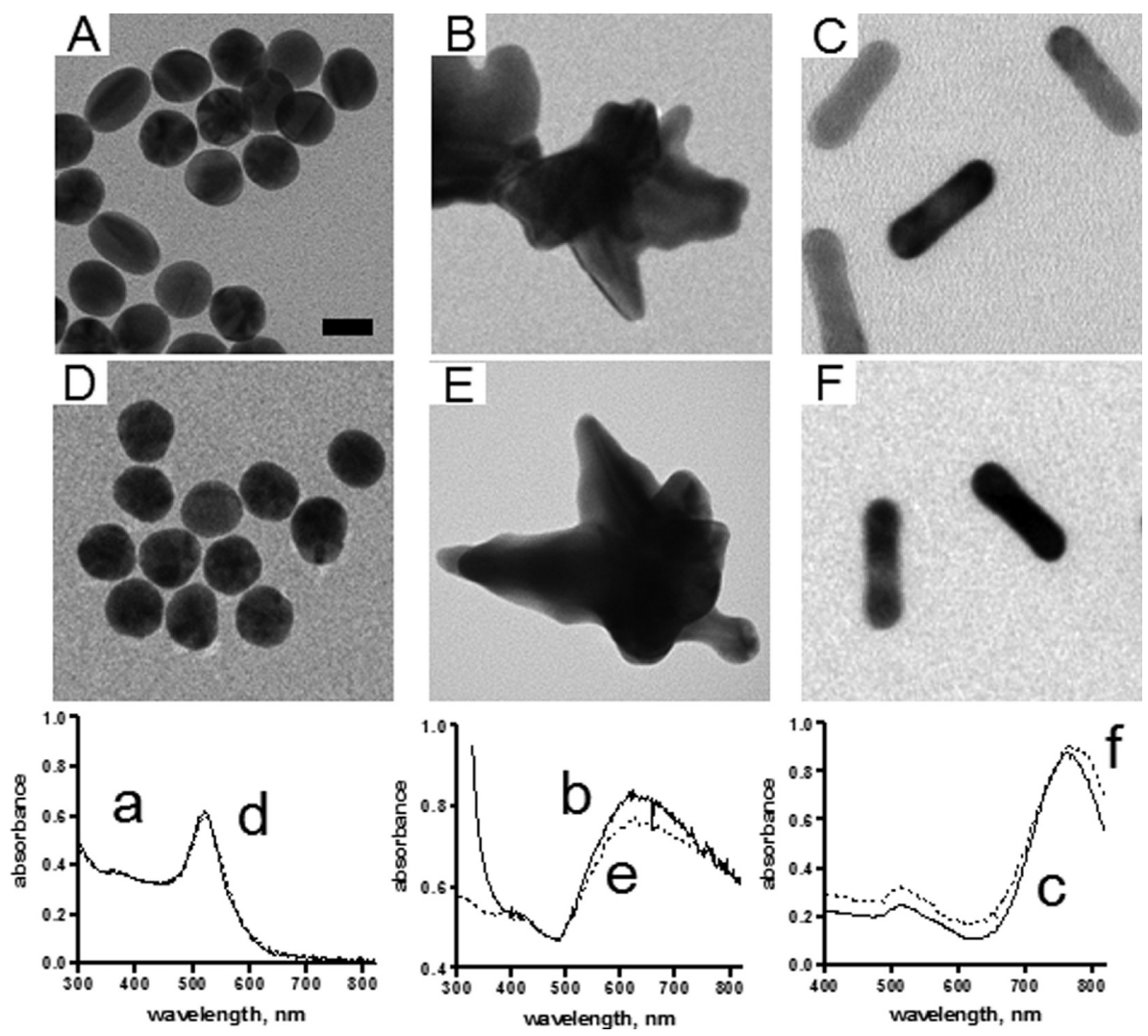

Figure 1. Transmission electron microscopic images and surface plasmon extinction spectra of the gold nanoparticles. Top panel: CTAB-covered spherical (A), urchin (B), and rod (C) GNPs. Bottom panel: PEGylated spherical (D), urchin (E), and rod (F) GNPs. Scale bar is representative for all panels $(20 \mathrm{~nm}) .(a-f)$ Corresponding spectra. Solid line, CTAB-covered GNPs; dashed line, PEGylated particles.

compared to spherical GNPs. The procedure of PEGylation resulted in an $8 \mathrm{~nm}$ red shift of the plasmon band, and a change of the $\zeta$ potential from a positive $(+39.2$ $\pm 0.4 \mathrm{mV})$ to a slightly negative value $(-9.7 \pm 0.6 \mathrm{mV})$.

The rod GNPs prepared with CTAB were $42.9 \pm 6.3$ $\mathrm{nm}$ long and $11.9 \pm 2.0 \mathrm{~nm}$ wide (aspect ratio 1:3.6, Figure 1B). Suspensions of the rods in water presented a dual plasmon band with the longitudinal extinction band at $762 \mathrm{~nm}$ (Figure 1b) and the transversal extinction band around $514 \mathrm{~nm}$. The longitudinal band shifted to $770 \mathrm{~nm}$ upon PEGylation. The surface modification was further confirmed by the shift of $\zeta$ potential from $+46.6 \pm 3.3$ to $-23.0 \pm 0.3 \mathrm{mV}$.

The three shapes were chosen not only for their optical but also for their geometrical differences. The elongated shape of the rods, the spiky structure of the urchins, the differences in surface area and curvatures can play a significant role in their interaction with the cells.

\section{Relationship between Gold Nanoparticles Surface} Coating/Morphology and Cytotoxicity. The effect of shape and surface coating on GNP-mediated cytotoxicity was assessed in a microglial cell line model, N9 cells (Figure 2)..$^{43}$ The effect of GNP spheres, rods, and urchins with two different surface coatings, CTAB and PEG, on cellular metabolic activity was assessed over a period of $24 \mathrm{~h}$ using the MTT assay. Significant decreases in mitochondrial metabolic activity were observed, in particular,

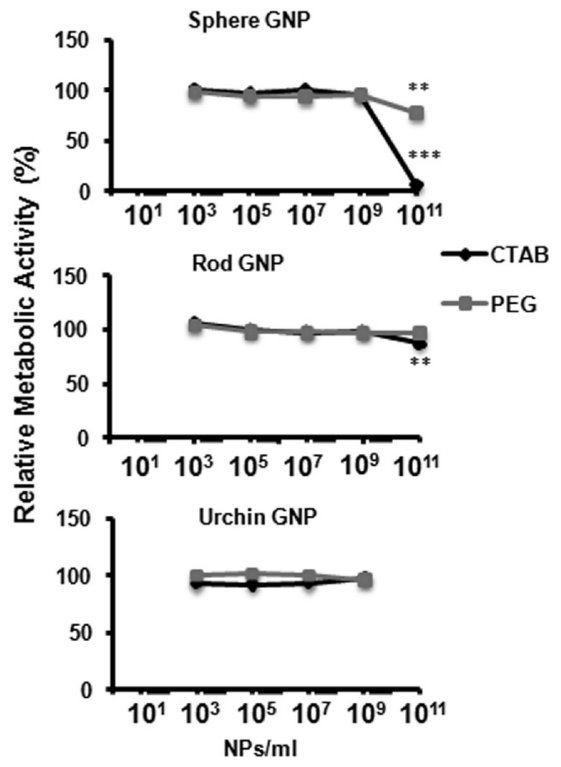

Figure 2. Gold nanoparticle (GNP) cytotoxicity in a microglial (N9) cell line. Cells were treated with varying concentrations of sphere, rod, and urchin GNPs coated with either CTAB or PEG $\left(10^{3}-10^{11} \mathrm{NPs} / \mathrm{mL}\right)$. Metabolic activity, as measured using the MTT assay, was made relative to untreated control cells $(=100 \%)$. Note that gold nanourchins were only tested up to $10^{9} \mathrm{NPs} / \mathrm{mL}$ due to their high content of gold; it is highly impractical to treat cells with $10^{11} \mathrm{NPs} / \mathrm{mL}$, which would be equivalent to over $500 \mathrm{ppm}$ of gold. Mean values and standard error of the means for triplicate measurements from three independent experiments $(N=9)$ are shown. Significant differences: ${ }^{*} p<0.05 ;{ }^{* *} p<0.01 ;{ }^{* * *} p<0.001$. 
with spherical GNPs and, in general, for CTAB-coated GNPs. Spherical GNPs were found to be significantly toxic to microglial cells at $10^{9} \mathrm{NPs} / \mathrm{mL}(6 \pm 0.1 \%$ for CTAB and $78 \pm 1.3 \%$ for PEG; $p<0.001$ ). In contrast, rod and urchin GNPs were relatively innocuous; only the CTAB-coated rods were found to be slightly toxic at $10^{11} \mathrm{NPs} / \mathrm{mL}(87 \pm 3.2 \% ; p<0.01)$. Thus our results (i) confirm that positively charged nanomaterials tend to exhibit greater toxicity, often credited to their increased uptake efficiency, ${ }^{44}$ and (ii) suggest that independent of the shape, at concentrations of $\leq 10^{9} \mathrm{NPs} / \mathrm{mL}$, GNPs are minimally toxic to microglial (N9) cells.

While bulk metallic gold, in general, is accepted as nontoxic and widely used in dentistry, for example, the size and surface of colloidal gold are such distinguishing properties that they should be considered in the context of interactions with living cells and organisms. Colloidal gold nanoparticles are stabilized electrostatically or sterically, which requires the presence of stabilizing molecules on their surface, such as CTAB, a cationic surfactant with membrane-compromising properties. CTAB in itself is toxic to the cells at $\sim 10 \mathrm{nM}$ concentration. ${ }^{45}$ The data on gold-bound $C T A B$ remain controversial: some groups reported it to be harmless, ${ }^{45,46}$ some found it toxic. ${ }^{42}$ In the latter case, overcoating the particles with PEG, phosphatidylcholine, or polystyrene sulfonate (PSS) was reported to reduce cytotoxicity significantly. ${ }^{42,47,48}$ It was reported that the extent of internalized rod GNPs with CTAB on their surface was 10 to 15 times higher than in the case of PEGylated rod GNPs. In our studies, CTAB-coated gold spheres ( $10^{11} \mathrm{GNPs} / \mathrm{mL}$ ) lead to marked neural cell loss $24 \mathrm{~h}$ after exposure, while CTAB-coated gold rods exhibited a more modest reduction in viability, likely due to the increased uptake of spheres supporting the findings by Chan's group. ${ }^{29}$

Dark-Field Microscopy and Hyperspectral Analysis of Gold Nanoparticles in Microglial Cells. Next, we performed intracellular imaging of GNPs using high contrast dark-field imaging (Figure 3 and Supporting Information Figure S1). Microglial cells seeded on coverslips were treated with $10^{9} \mathrm{GNPs} / \mathrm{mL}$ for $12 \mathrm{~h}$, fixed, and mounted onto glass slides, after which uptake was assessed by darkfield microscopy, using a CytoViva microscope setup and hyperspectral analysis software (see Methods). As noted in Figure $3 A, B, C T A B-c o a t e d$ rods and PEG-coated urchins, respectively, were taken up, supporting the notion that internalization of these GNPs by microglial cells does not compromise their viability (see Figure 2). Urchin GNPs were not only readily internalized by microglial cells, but they were also excellent contrast agents (Figure $3 \mathrm{~B}$ ) relative to spheres (Supporting Information Figure $1 A, B)$; their outstanding brightness compared to PEGylated gold spheres and rods is likely the result of their relatively large size and bumpy morphology, which may provide multiple "hot spots" for field enhancement. The larger diameter is associated with a
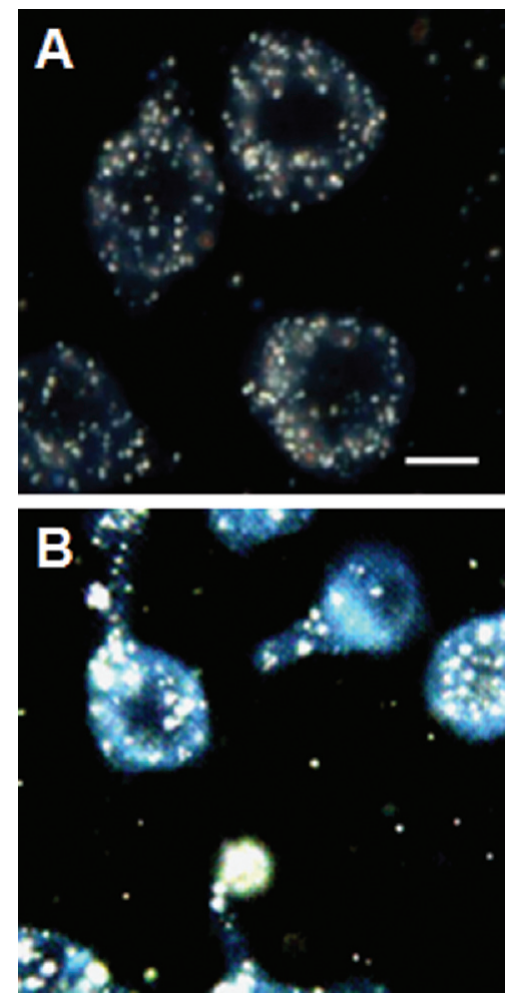

Figure 3. High contrast dark-field imaging of internalized gold nanoparticles (GNPs) in microglial (N9) cells. Microglial cells (N9) were treated with CTAB-coated rods (A) and PEGcoated urchins (B). Following treatment with $10^{9} \mathrm{GNPs} / \mathrm{mL}$ for $12 \mathrm{~h}$ at $37^{\circ} \mathrm{C}$, cells on coverslips were fixed with paraformaldehyde, mounted onto glass slides, and imaged using the CytoViva setup for high sensitivity dark-field imaging (see Methods for further detail). Scale bar in first panel is $10 \mu \mathrm{m}$ and is representative for both panels.

higher scattering coefficient, and the sharp geometrical features cause a quasi-electrostatic "crowding" of many electric field lines that leads to a tremendous field enhancement, the so-called lightning rod effect. The combined effect of these physical parameters provides for high contrast in optical microscopy.

The extent of internalization and signal intensity in the dark field was similar for gold nanorods and urchins. In an attempt to quantify the internalized GNPs, we performed an ICP-AES analysis of gold on cells treated with $10^{9} \mathrm{GNPs} / \mathrm{mL}$ for all three shapes and two surfaces. The gold content in the cells treated with gold nanourchins were easily measured, whereas the signal for intracellular gold from spheres and rods was at the detection limit. ICP-AES measurements of microglia exposed to gold nanourchins with PEG and CTAB yielded similar results; $4 \mu \mathrm{g} / \mathrm{mL}$ and $3.55 \mu \mathrm{g} / \mathrm{mL} A u$ in the cells treated with CTAB and PEG modified urchin GNPs, respectively. To confirm the results obtained with darkfield microscopy, live imaging with two-photoninduced luminescence (TPL) was used for all six different types of GNPs.

Two-Photon Luminescence Imaging of Rod GNPs in Live Cells. Two-photon-induced luminescence was used to visualize the intracellular localization of internalized GNPs in 

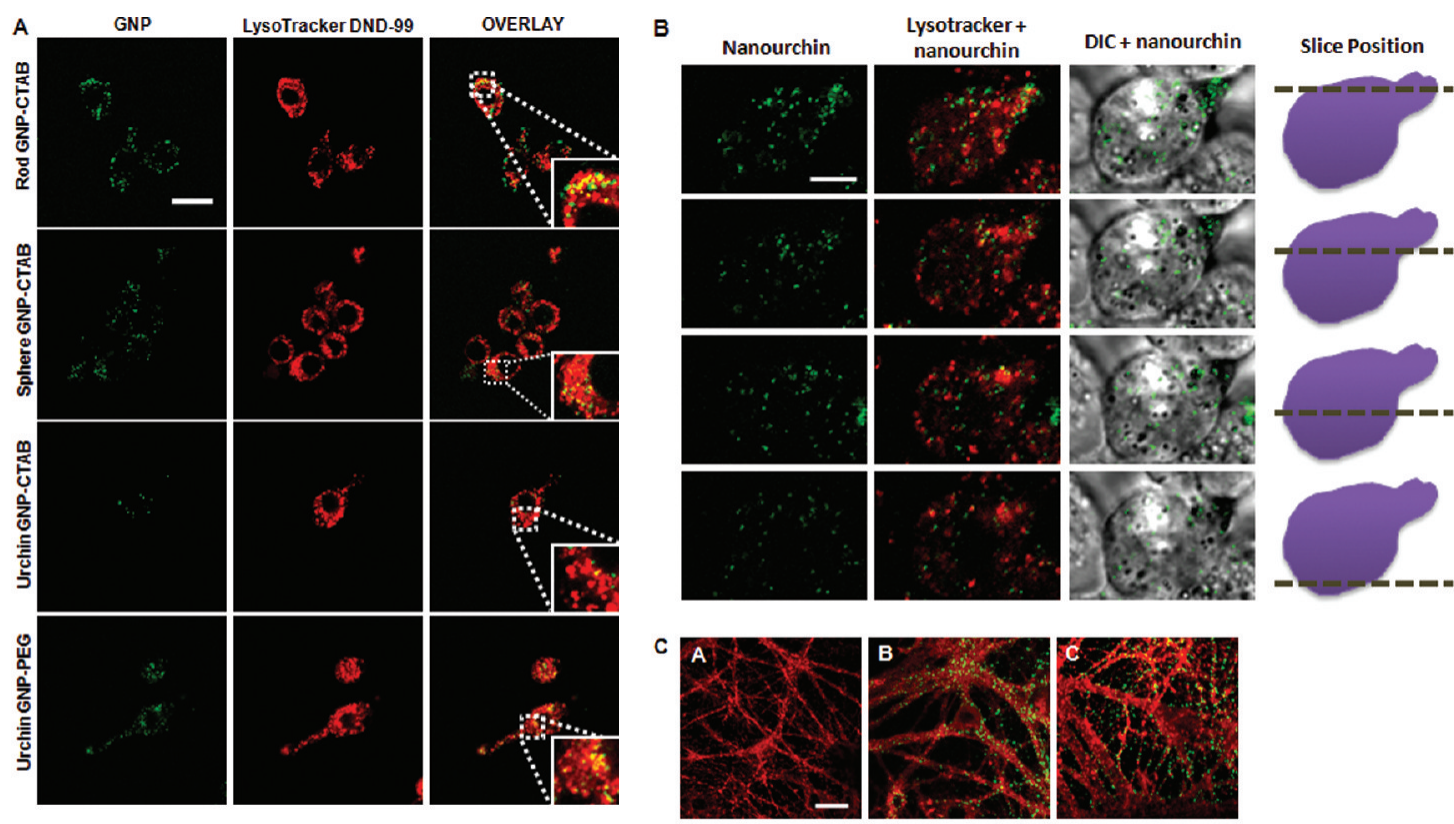

$\mathrm{D}$
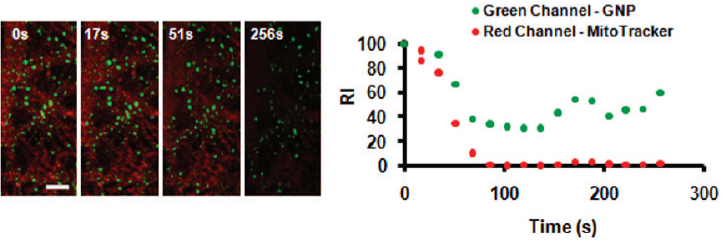

Figure 4. Two-photon luminescence (TPL) imaging of internalized gold nanoparticles in microglia and primary hippocampal neurons. $(A, B)$ Internalization of PEG- and CTAB-coated GNPs in microglia. Microglia (N9) were treated with GNPs $\left(10^{9}\right.$ $\mathrm{NPs} / \mathrm{mL}$ for $12 \mathrm{~h}$ at $37^{\circ} \mathrm{C}$ ) and stained with LysoTracker Red DND-99. TPL images were acquired in live cells using a twophoton microscope. (A) Note that GNPs are primarily found in the cytosol and, to a certain extent, colocalize with lysosomal compartments (indicated by enlarged inset image). Scale bar $(20 \mu \mathrm{m})$ in control overlay image is representative for all panels. See also Supporting Information Figure S2. (B) Images acquired along the $z$ axis of microglia treated with PEG-coated urchins demonstrate that the GNP signal is detectable within all slices of the $z$ stack, providing evidence for the internalization of urchin GNPs. Last column of panels provides a schematic illustrating the position along the $z$ axis relative to the cell. Scale bar $(5 \mu \mathrm{m})$ in the first panel is representative for all panels. (C) TPL imaging of primary hippocampal neurons treated after 21 days in vitro with PEG-coated (B) and CTAB-coated (C) rod GNPs $\left(10^{9} \mathrm{NPs} / \mathrm{mL}\right)$ for up to $4 \mathrm{~h}$. Neurons were stained with MitoTracker green FM (pseudocolored red). Untreated control cells can be seen in A. Imaging was performed with a twophoton microscope. The scale bar in the control panel is representative for all four panels. (D) Photobleaching experiment with CTAB-coated rod GNPs confirming that the signal detected in the red and green channel are from two separate sources. The scale bar in the first panel is representative for all panels. (b) Plot of the changes in relative intensity over time in the green and red channel, separately, measured from the photobleaching experiment in a. The fluorescent intensity in each channel at every time-point was normalized to the fluorescence in the respective channel at time $=0 \mathrm{~s}$ (i.e., $100 \% \mathrm{RI}$ at $0 \mathrm{~s}$ ).

live microglia and primary neuronal cells. Microglia were treated with all six different types of GNPs $\left(10^{9}\right.$ $\mathrm{NPs} / \mathrm{mL}$ ) for 4 to $12 \mathrm{~h}$, washed, and stained with LysoTracker for labeling of acidic compartments, primarily lysosomal organelles. CTAB-coated spheres and rods internalized readily and partly colocalized with acidic lysosomal compartments (Figure 4A, see insets). Spheres and rods with PEGylated surfaces did not internalize in microglial cells to any significant extent within $12 \mathrm{~h}$ in microglial cells (Supporting Information Figure S1), confirming the results from dark-field imaging (Figure 3). Interestingly, however, the internalization of urchin GNPs occurred independently of surface coating; both PEG- and CTAB-coated urchin GNPs were internalized by microglial cells within the same time period (12 h). They were mainly dispersed in the cytosol and to a small extent $(<10 \%)$ localized within lysosomes (Figure 4A, inset images). By acquiring images along the $z$ axis of cells, urchin GNPs were detectable in slices at all levels, suggesting their true intracellular location and not an unspecific association with the surface of the microglial cells (Figure 4B).

We subsequently used delicate primary neurons isolated from rodent hippocampi to determine whether GNPs are retained within the neuritic arbors and whether they had an effect on somatic and dendritic morphology. Photomicrographs of two-photon luminescence images of three week old primary neurons treated for $4 \mathrm{~h}$ with rod GNPs modified with $C T A B$ and PEG chains are shown (Figure 4C). After incubation with the rod GNPs, the cells were stained with MitoTracker Green FM (pseudocolored red), in order to outline mitochondria along the cell body, the axon, the dendrites, and the spines of these neurons. Both rod GNP-CTAB and rod GNP-PEG decorate the dendrites of the neurons and appear to be internalized both along the 

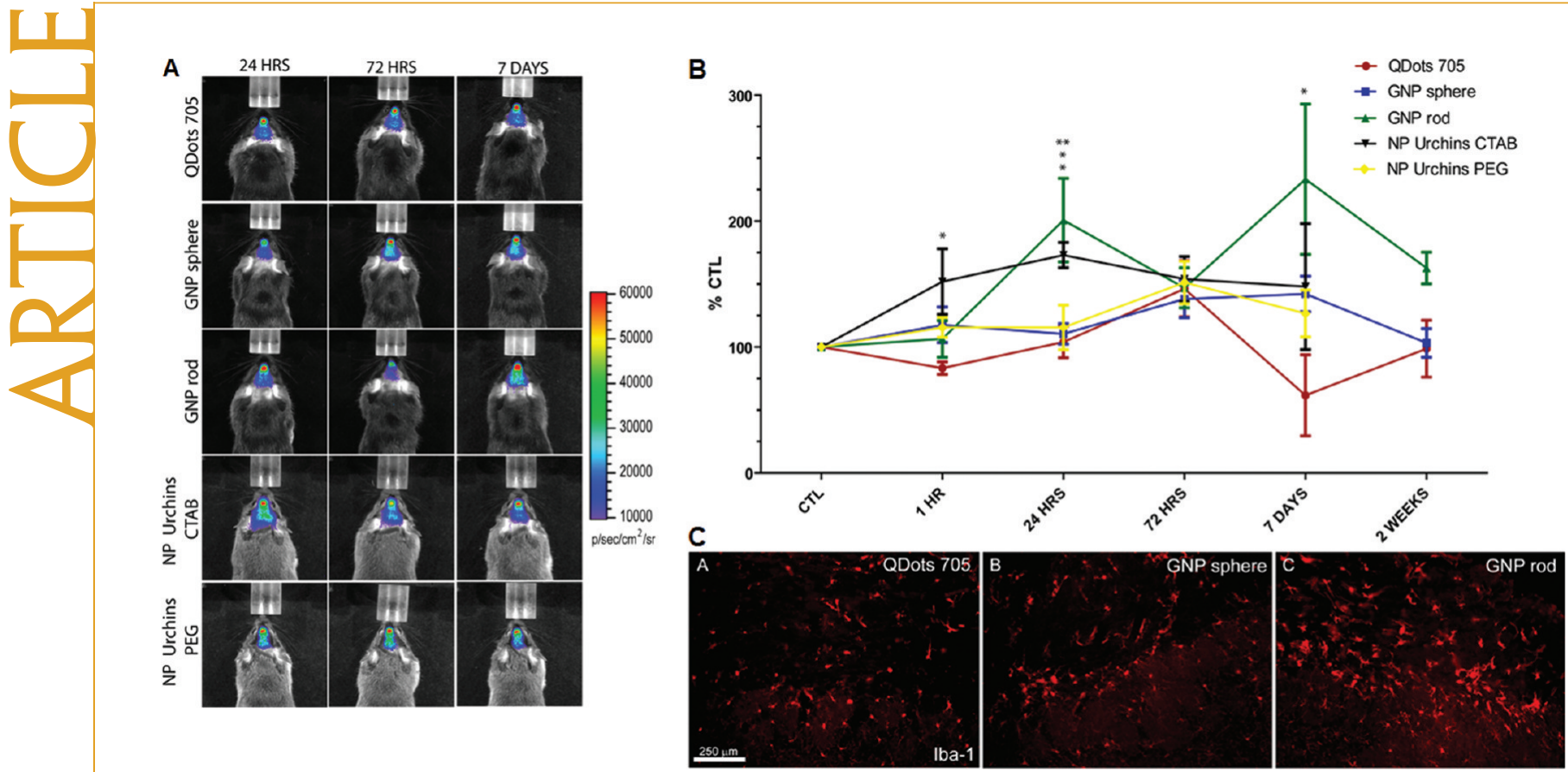

Figure 5. In vivo bioluminescence imaging of microglia in transgenic mice after intranasal administration of gold nanoparticles. (A) PEGylated gold spheres, rods, and urchins were administered intranasally ( $5 \mu \mathrm{L} /$ left nostril). PEGylated quantum dots (QD705) were administered in the same way and in the same amount ( $10^{12}$ nanoparticles $/ \mathrm{mL}$ ). Detectable fluorescence signal from QD705 (left, bottom panel) and absence of the signal from gold nanoparticles (left: top and middle panel). Representative pseudocolor bioluminescence images ( 24 h, 72 h, 7 days, and 14 days) are shown for PEGylated gold nanopheres (top four panels), gold rods (middle four panels), and QD705 (bottom four panels) after intranasal administration of the nanoparticles to the TLR-2-Fluc-GFP reporter mouse. Quantification scales of the total photon emission signal (photon $/ \mathrm{s} / \mathrm{cm}^{2} / \mathrm{sr}$ ) are shown at the right side from the images. (B) Time course of change in bioluminescence signal intensity in mice treated with gold nanoparticles (spheres, rods, and urchins) and also QD705. Note a biphasic activation of microglia caused by rod GNPs and small but significant microglia response to gold spheres. Ordinate: change in bioluminescence intensity relative to control animals ( $100 \%)$ receiving saline $(5 \mu \mathrm{L} /$ left nostril). Mean values and standard error of the means from four animals per group per time point are reported. Significant differences: ${ }^{*} p<0.05 ;{ }^{* *} p<0.01 ;{ }^{* * *} p<0.001$. (C) Microglial activation in the olfactory bulb after intranasal injection of nanoparticles. Representative photomicrographs of Iba-1 immunoreactivity in the olfactory bulb of TLR-2-Fluc-GFP mice 7 days after the intranasal administration of (A) QDots 705, (B) GNP sphere, or (C) GNP rod. By immunofluorescence, a strong lba-1 signal (in red) is observed in the (C) GNP rod group compare to (A) Qdots 705 and (B) GNP sphere group ( $n=4)$. Scale bar $=250 \mu \mathrm{m}$

neurites as well as within the cell body. No signal was detected in neurons treated with sphere or urchin GNPs (data not shown). To confirm that the signal detected in the green channel indeed originates from the rod GNPs, and that it is not a bleedthrough from the red channel, we carried out a photobleaching experiment. As seen in Figure 4D, the decay of the relative intensity in the red channel was markedly faster than the decay in the green channel, confirming that the source of the individual signals is indeed not the same.

Considering the specific shape of the neurons (small cell body, long processes), it is conceivable that relatively thin rods (only $12 \mathrm{~nm}$ in diameter) have a more favorable morphology for internalization, compared to the larger and spikier urchin structures. Given that uptake mechanisms between neurons and microglia are different, it is likely that urchins were phagocytosed by microglia, a process that does not take place along neuritic dendrites and arbors. One reason for this could be the relatively large size and spiky surface of nanourchins relative to nanorods. The urchins were estimated to have a surface about 10 times larger $\left(\sim 1.8 \times 10^{6} \mathrm{~nm}^{2} /\right.$ particle) than the rods and spheres. Their dimensions are at least twice the length of the rods and 3-4 times larger than the spheres.

Microglial Activation In Vivo by Gold Nanoparticles. In macrophage-like cells, such as microglia, the internalization capacity of biological and artificial nanoparticles heavily depends on their phagocytic activity, which tends to be increased in the activated state. ${ }^{39,49}$ Therefore, to probe microglial activation by gold nanoparticles in vivo, we used a transgenic mouse model bearing the dual reporter system luciferase/green fluorescent protein under transcriptional control of a murineTLR-2 promoter. ${ }^{50,51}$ Assessment of the bioluminescence was performed at different times after GNP administration (Figure 5). PEGylated QDs were used both as a control for PEGylated surfaces of gold nanoparticles and as an independently detectable fluorescent control. Moreover, these fluorescent nanoparticles were previously reported not to significantly activate astrocytes in the central nervous system in vivo. ${ }^{52}$

Spherical, rod, and urchin GNPs administered intranasally to the transgenic mice reveal changes of microglia with distinctly different temporal pattern (Figure $5 A, B)$ : spherical GNPs cause a small but detectable activation of microglia after $24 \mathrm{~h}$, and the activity remained 
sustained for a week (Figure 5B). In contrast, rod GNPs caused biphasic activation with one early peak at $24 \mathrm{~h}$ and the other after one week. PEGylated urchin GNPs did not significantly activate microglia at any time, while CTAB-coated urchin GNPs caused a transient activation that disappeared after a week. The bioluminescent signal in mice treated with QD705 was significantly lower than that from animals treated with rod GNPs with the maximal bioluminescence signal one week after nanoparticle treatment but still significantly smaller than that of gold nanospheres (Figure 5B). The animals were sacrificed after one week, and their olfactory bulb was dissected and immunostained using cell-specific antibodies (lba-1) recognizing microglia (Figure 5C). In accord with the peak at 7 days (Figure 5B), markedly enhanced number of Iba-1-immunopositive microglia in the olfactory bulb indicated microgliosis in this brain region. Closer inspection of the individual sections did not reveal any other remarkable morphological abnormality. The results suggest that nanourchins are preferentially taken up by microglia rather than by neurons, presumably as a consequence of their morphology. This finding points toward the possible exploitation of nanourchins in real-time multiphoton imaging of microglia and/or as delivery vehicles for pharmacological agents to regulate microglia activation and its impact on neuronal functions.

In speculation of what may cause the difference in microglial response to the different GNPs, we compared some of the physical properties of the spherical, rod, and urchin GNPs. We found that the gold nanorods have a surface/volume ratio of 1.14, about 5 times larger than the surface/volume ratio of spherical GNPs (0.26), although the surface areas of the two types of particles are comparable (1830 and $1680 \mathrm{~nm}^{2} /$ particle, respectively). The nanourchin GNPs have an estimated surface $\sim 10$ times larger than rods or spheres, but their surface/volume ratio is $\sim 10$ times smaller ratio than rods (in the range of $0.1-0.2$ ). Moreover, rod GNPs possess a large number of (100) surface sites which show a high catalytic activity, ${ }^{53}$ in particular, toward the generation of NO from endogenous RSNOs in blood serum, causing oxidative stress in cells. ${ }^{54}$ Electrochemical experiments also demonstrated that the most active single-crystal electrode in basic media is the $\mathrm{Au}(100)$ electrode, whereas the $\mathrm{Au}(111)$ electrode is the least active. ${ }^{53}$ These parameters (high surface/volume ratio, highly active surface facets) could contribute to the elevated microglia activation caused by rod GNPs.

Toll-like Receptor 2 (TLR-2) Up-Regulation and Stimulation of Cytokine Release In Vitro. Since the in vivo data showed that GNPs induce TLR-2 promoter activity in a shape- and surface-dependent manner, we tested in vitro the effect of various GNPs on TLR-2 protein expression (Figure 6) using murine microglial N9 cells because they show responses to insults, trophic factors, and other stimuli similar to the responses of primary microglia..$^{55}$ Treating
A
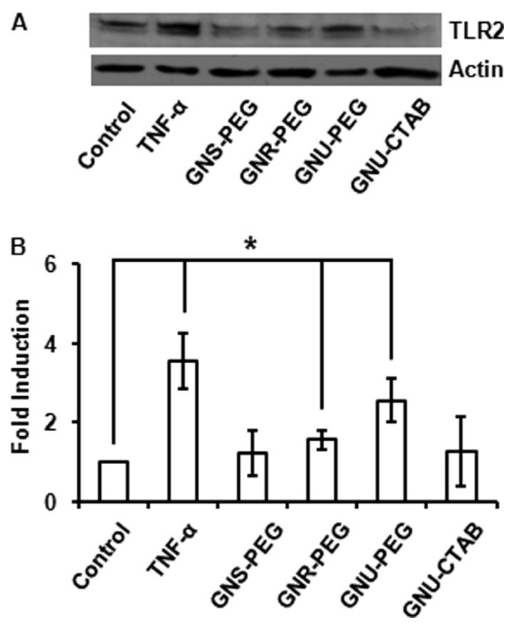

Figure 6. TLR-2 upregulation by urchin GNPs $\left(10^{9} \mathrm{NPs} / \mathrm{mL}\right)$ in vitro. (A) Representative Western blot for TLR-2 with actin for normalization of protein loading. (B) Densitometry measurements, tabulated from three independent experiments, are normalized to actin and expressed relative to control, where control is set to a value of 1 . Mean values and standard error of the means are reported.

microglial N9 cells with PEGylated urchin GNPs for $24 \mathrm{~h}$ led to a 2.6-fold ( $p<0.05$ ) induction in TLR-2 expression, while rod GNPs led to a more modest 1.5-fold ( $p<0.05$ ) increase. Thus far, the mechanisms resulting in the induction of TLR-2 are not fully understood in microglial cells. It has been previously shown that tumor necrosis factor $\alpha$ (TNF- $\alpha$ ), a pro-inflammatory cytokine, is secreted from primary microglial cells and is sufficient to cause TLR-2 upregulation. ${ }^{56}$ It was further demonstrated that both caffeic acid, a general inhibitor of the pro-inflammatory transcription nuclear factor $\kappa$ enhancer binding protein (NFkB), and SC-514, an inhibitor of IkappaB kinase 2 (IKK2 ), abrogate the effects of TNF- $\alpha$ on TLR-2 induction. We therefore used these pharmacological tools to confirm the involvement of NFkB. Importantly, downstream effects of TLR-2 activation in macrophages involve the release of pro-inflammatory cytokines, such as interleukins 1 and TNF- $\alpha$, via NFkB, ${ }^{57}$ as well as the induction of autophagy and phagocytosis. ${ }^{58}$

To assess the effects of TLR- 2 induction, we screened pro-inflammatory cytokines following treatment with GNPs. A profiling ELISA array was used to test for the release of 12 different cytokines, including interleukins (IL) $1 \alpha, 1 \beta, 2,6,8,10,12,17 \alpha$, tumor necrosis factor $\alpha$ (TNF $\alpha)$, granulocyte macrophage colony-stimulating factor (GM-CSF), interferon $\gamma$ (IFN- $\gamma$ ), and macrophage colony-stimulating (M-CSF). The IL- $1 \alpha$ and GM-CSF were the only detectable cytokines after $6 \mathrm{~h}$ incubation with GNPs. PEGylated sphere and rod GNPs stimulated the release of GM-CSF $(11.1 \pm 0.62,11.2 \pm 0.44 \mathrm{pg} / \mathrm{mL}$ respectively, $p<0.001$ ), while urchin GNPs significantly reduced $\mathrm{GM}-\mathrm{CSF}$ secretion to barely detectable levels $(\mathrm{PEG}=0.3 \pm 0.01, \mathrm{CTAB}=0.0 \pm 0.03 \mathrm{pg} / \mathrm{mL}$ ) (Figure $7 A)$. In contrast, IL-1 $\alpha$ release was stimulated only by urchins (PEG $=91.4 \pm 0.13, C T A B=46.8 \pm 0.34 \mathrm{pg} / \mathrm{mL}$, $p<0.001)$ and was sensitive to caffeic acid phenethyl 

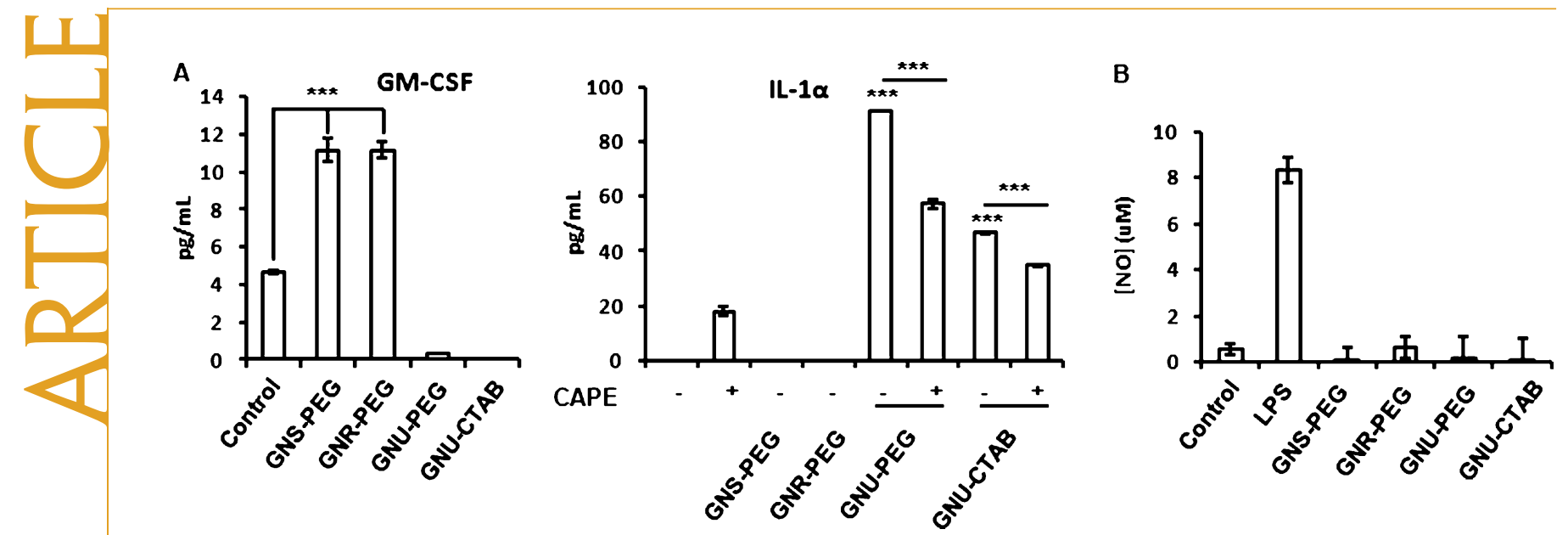

Figure 7. Cytokine release and nitric oxide (NO) production by microglia stimulated with GNPs. Supernatants from cells treated with $10^{9}$ GNPs/mL for $6 \mathrm{~h}$ at $37^{\circ} \mathrm{C}$ were analyzed for granulocyte macrophage colony-stimulating factor (GM-CSF) (A) and interleukin 1 alpha (IL$1 \alpha$ ) (B) by ELISA assay and for NO production by the Griess reaction (C). LPS (100 ng/mL) is lipopolysaccharride. Mean values and standard error of the means are reported. Significant differences: ${ }^{*} p<0.05 ;{ }^{* *} p<0.01 ;{ }^{* *} p<0.001$.

ester (CAPE, an inhibitor of NFkB signaling) treatment $(+\mathrm{CAPE}-\mathrm{PEG}=57.3 \pm 1.54, \mathrm{CTAB}=34.8 \pm 0.41 \mathrm{pg} /$ $\mathrm{mL}, p<0.001$ compared to -CAPE). Furthermore, GNP addition caused no significant increase in NO production, relative to control, while lipopolysaccharide (LPS), a TLR4/6 ligand, resulted in a significant release of NO. Interestingly, TLR-2 ligands (i.e., lipoteichoic acid) can cause the release of IL- $1 \alpha$ and GM-CSF, ${ }^{59}$ and given that GNP-mediated IL-1 $\alpha$ secretion was reduced by inhibiting NFkB, it is plausible that urchin GNPs may be acting through TLR-2 to activate microglia. Moreover, previous work indicates that TLR-2 activation potentiates microglial responses to chemoattractants, ${ }^{56} \mathrm{~mol}-$ ecules responsible for the recruitment of microglia to brain lesions in pathological states. These studies also indicate that activation of TLR-2 augments clearance of pathological insults, such as the toxic $\beta$-amyloid $(A \beta)$ peptide found in brains affected by Alzheimer's disease, suggesting a therapeutic potential for TLR-2 agonists. A TLR-2-dependent increase in microglial phagocytic activity could explain the efficient uptake of nanourchins by microglia (Figure $4 A, B$ ). These data thus further suggest possible therapeutic uses of nanourchins as modulators of microglia activation both in vitro and in vivo.

In summary, we have prepared gold nanoparticles (GNPs) with different nanogeometries but with identical surface coating (PEG or CTAB). We have shown that microglia internalize the GNPs with no sign of acute cytotoxicity ( $\leq 10^{9} \mathrm{GNPs} / \mathrm{mL}$ ) and that the extent of internalization appears to depend on the GNP shape. Rod GNPs with CTAB or PEG on their surface were internal- ized by live primary hippocampal neurons. They were imaged with excellent signal-to-noise ratio by twophoton-induced luminescence (TPL). In transgenic mice, rod and urchin GNPs caused transient microglial activation, and further studies in vitro indicate that the mechanisms of activation depend, at least in part, on GNP shape. This study provides evidence that (i) tuning of gold nanoparticle geometry can serve as a modality in regulating nanoparticle-cell interactions and, more specifically, (ii) nanourchins may have direct therapeutic applications in pathological conditions that respond to enhanced microglial activity.

Future Perspectives. Our studies point to the need to investigate in detail the potential roles that gold nanourchins could play in mechanistic and therapeutic applications in the central nervous system (CNS). Some of the relevant questions in this regard include the following: Which ones among the many other microglia receptors on the cell surface are involved in microgliagold nanoparticle interactions? Can nanourchins be internalized by neurons if a specific ligand for neurons is linked to the gold nanosurface? Does the shape, size, and surface also modulate subtle epigenetic changes observed with nanoparticle treatment, ${ }^{60}$ in addition to the transient microglia activation reported in this study? Could the single or repeated exposure to minute quantities of gold nanoparticles lead to the stimulation of neuronal circuitry and enhanced function in neurodegenerative states? Our group is presently focused on answering these questions and uncovering potential therapeutic or diagnostic applications of nanourchins in various disease states of the CNS.

\section{METHODS}

Materials. Gold chloride trihydrate was obtained from Alfa Aesar. Sodium citrate, silver nitrate, sodium borohydride, L-ascorbic acid (AA), gelatin (from bovine skin, type B), potassium carbonate, 11-mercaptoundecanoic acid (MUA), 1-ethyl-3-(3dimethylaminopropyl)carbodiimide (EDC),
$\mathrm{N}$-hydroxysuccinimide (NHS), and 3-(4,5-dimethylthiazol-2-yl)2,5-diphenyltetrazolium bromide (MTT) were purchased from Sigma Aldrich. Hexadecyltrimethylammonium bromide (CTAB) was purchased from Fluka. $\alpha$-Methoxy- $\omega$-mercapto poly(ethylene glycol) (MeO-PEG-SH, $5000 \mathrm{~g} / \mathrm{mol}$ ) was obtained from IRIS Biotech $\mathrm{GmbH}$, Germany. Green anionic CdTe quantum dots $\left(\lambda_{\mathrm{em}}\right.$ 
$=530 \mathrm{~nm}$; quantum yield $=0.05, \zeta$ potential $=-38.60 \mathrm{mV}$ ) were prepared as described previously. ${ }^{52}$ Trypan blue (15250-061) and MitoTracker Green FM (M-7514) were purchased from Invitrogen. Tumor necrosis factor $\alpha$ (TNF- $\alpha$ ) was purchased from BioLegend. In all experiments, deionized Millipore water was used.

Preparation of Gold Nanoparticles. CTAB-coated spherical GNPs $(d=23.1 \pm 1.1 \mathrm{~nm}$ ) were prepared by adding an aqueous icecold $\mathrm{NaBH}_{4}$ solution $(0.500 \mathrm{~mL}, 0.01 \mathrm{M})$ to a mixture of aqueous $\mathrm{HAuCl}_{4} \cdot 3 \mathrm{H}_{2} \mathrm{O}(0.125 \mathrm{~mL}, 0.01 \mathrm{M})$ and an aqueous solution of CTAB $(4.375 \mathrm{~mL}, 0.075 \mathrm{M})$. The seed growth was allowed to proceed for $2 \mathrm{~h}$. After this time, an aliquot of the seed solution was added to a solution obtained by adding aqueous CTAB $(1.6 \mathrm{~mL}$, $0.10 \mathrm{M})$, aqueous $\mathrm{HAuCl}_{4} \cdot 3 \mathrm{H}_{2} \mathrm{O}(2 \mathrm{~mL}, 0.01 \mathrm{M})$, an aqueous $\mathrm{AA}$ solution $(0.6 \mathrm{~mL}, 0.10 \mathrm{M})$ to $90 \mathrm{~mL}$ water, followed by the aged seed solution $(0.1 \mathrm{~mL}) .{ }^{61}$ Immediately upon addition of the seed solution, the mixture was mixed gently for $10 \mathrm{~s}$. It was then kept undisturbed for at least $3 \mathrm{~h}$. The solutions were kept at $27^{\circ} \mathrm{C}$ (in a water bath) throughout the entire procedure in order to prevent the crystallization of CTAB. At the end of the reaction, the mixture was centrifuged by an Eppendorf centrifuge model 5403 (6000 $\mathrm{rpm}, 60 \mathrm{~min})$. The residue was redispersed in water $(5 \mathrm{~mL})$.

Rod GNPs were synthesized by a scaled-up version of the seeded growth method described previously. ${ }^{62}$ Gold seeds were prepared by adding an aqueous ice-cold $\mathrm{NaBH}_{4}$ solution $(0.600$ $\mathrm{mL}, 0.01 \mathrm{M}$ ) to a solution obtained by adding aqueous

$\mathrm{HAuCl}_{4} \cdot 3 \mathrm{H}_{2} \mathrm{O}(0.250 \mathrm{~mL}, 0.01 \mathrm{M})$ to an aqueous solution of CTAB $(7.5 \mathrm{~mL}, 0.10 \mathrm{M})$. The seed growth was allowed to proceed for

$2 \mathrm{~h}$. After this time, an aliquot of the seed solution was added to a solution obtained by mixing, first, aqueous CTAB $(95 \mathrm{~mL}, 0.10$ $\mathrm{M})$, aqueous $\mathrm{HAuCl}_{4} \cdot 3 \mathrm{H}_{2} \mathrm{O}(4 \mathrm{~mL}, 0.01 \mathrm{M})$, and aqueous $\mathrm{AgNO}_{3}$ $(0.6 \mathrm{~mL}, 0.01 \mathrm{M})$ and, last, an aqueous AA solution $(0.64 \mathrm{~mL}, 0.10$ $\mathrm{M})$. Immediately upon addition of the seed solution, the mixture was mixed gently for $10 \mathrm{~s}$. It was then kept undisturbed for at least $3 \mathrm{~h}$. The solutions were kept at $27^{\circ} \mathrm{C}$ (in a water bath) throughout the entire procedure in order to prevent the crystallization of CTAB. At the end of the reaction, the mixture was centrifuged by an Eppendorf centrifuge model 5403 (9000 rpm, 90 $\mathrm{min}$ ). The residue (rod GNP) was redispersed in water, and MeOPEG-SH $(12 \mu \mathrm{L}, 25 \mathrm{mM})$ was added to this suspension $(0.3 \mathrm{~mL})$. The mixture was kept overnight. It was subjected to centrifugation (14000 rpm $20 \mathrm{~min}$ ). The residue was redispersed in water $(0.5 \mathrm{~mL}) .^{63,64}$ The concentration of atomic gold in the rod GNP suspension was determined by inductively coupled plasmon atomic emission spectroscopy (ICP-AES).

CTAB-coated urchin GNPs were also prepared by seed mediated process. ${ }^{20} \mathrm{Gold}$ seeds were synthesized by adding an aqueous ice-cold $\mathrm{NaBH}_{4}$ solution $(0.1 \mathrm{~mL}, 0.03 \mathrm{M})$ to a $10 \mathrm{~mL}$ solution of aqueous $\mathrm{HAuCl}_{4} \cdot 3 \mathrm{H}_{2} \mathrm{O}\left(2.5 \times 10^{-4} \mathrm{M}\right)$ and trisodium citrate $\left(2.5 \times 10^{-4} \mathrm{M}\right)$. The seed growth was allowed to proceed for $4 \mathrm{~h}$. For growth solution, $0.75 \mathrm{~mL}$ of cyclohexane and $1.0 \mathrm{~mL}$ of acetone were added into $50 \mathrm{~mL}$ of aqueous solution containing aqueous $\mathrm{CTAB}(30 \mathrm{~g} / \mathrm{L})$ and aqueous $\mathrm{HAuCl}_{4} \cdot 3 \mathrm{H}_{2} \mathrm{O}(2.5 \times$ $10^{-4} \mathrm{M}$ ). Without delay, $20 \mathrm{~mL}$ was taken from the lower portion of the phase separated solution and combined with the gold seed suspension $(0.12 \mathrm{~mL}), \mathrm{AgNO}_{3}$ aqueous solution $(0.01 \mathrm{~mL}$, $0.02 \mathrm{M}$ ), and freshly prepared aqueous ascorbic acid ( $1 \mathrm{~mL}, 0.1$ M). The suspension was allowed to stand for $3 \mathrm{~h}$, while its color gradually changed. The solutions were kept at $27^{\circ} \mathrm{C}$ (in a water bath) throughout the entire procedure in order to prevent the crystallization of CTAB. At the end of the reaction, the mixture was centrifuged by an Eppendorf centrifuge model 5403 (6000 $\mathrm{rpm}, 10 \mathrm{~min})$. The residue was redispersed in water $(5 \mathrm{~mL})$.

Instrumentation. UV - visible absorption spectra were recorded with an 8452A Agilent photodiode array spectrometer. ICP-AES data were acquired using a Jobin Yvon/Horiba JY200 instrument and analyzed with the ICP sofware "ICP Analyst v5.2". The gold ray wavelength was at $267.595 \mathrm{~nm}$. Transmission electron micrographs (TEM) of the nanoparticles were obtained using a FEI TEC$\mathrm{NAl}$ electron microscope operating at $120 \mathrm{kV}$. The supporting grids were Formvar-covered, 200-mesh copper grids. The size of the nanoparticles was determined from the electron microscopic images using a free ImageTool version 3.00, downloaded from http://ddsdx.uthscsa.edu/dig/download.html. About 100 particles were measured for each sample.
Cell Culture and Treatments. N9 microglial cells were cultured in Iscove's modified Dulbecco's medium (IMDM; Gibco) supplemented with $5 \%(\mathrm{v} / \mathrm{v})$ fetal bovine serum (FBS; Gibco) and $1 \%$ (v/v) penicillin/streptomycin (Gibco). Cells were seeded at $1 \times$ $10^{5}$ cells/well in 24-well cell culture plates (Sarstedt) and treated $24 \mathrm{~h}$ later. Gold nanoparticles and quantum dots were diluted in culture media to achieve working concentration. Viability assays were performed up to a maximum of $24 \mathrm{~h}$ after treatment. Primary hippocampal neuronal cultures were prepared from rats (postnatal day 1) and kept in serum-free conditioned medium for 21 days before they were used for two-photon imaging experiments. Rod GNPs were diluted directly in the well to a working concentration of $10^{9}$ particles $/ \mathrm{mL}$ for $4 \mathrm{~h}$. Prior to imaging, MitoTracker green FM was diluted to a working concentration of $100 \mathrm{nM}$ and cells were stained for $2 \mathrm{~min}$, after which they were washed once with fresh warm media.

MTT Assay. Cells were seeded at a density of $1 \times 10^{5}$ in a 24well cell culture plate (Sarstedt) and treated according to the standard protocol. ${ }^{65}$ After various time intervals, medium was removed and replaced with medium containing MTT $(500 \mu \mathrm{g} /$ $\mathrm{mL}$ ). Cells were incubated at $37^{\circ} \mathrm{C}$ for 60 min after which medium was removed. DMSO was added to lyse the cells and dissolve the formazan produced. Triplicates from each well were collected into a 96-well plate (Sarstedt), and the absorbance at $595 \mathrm{~nm}$ of each well was measured using a Benchmark microplate reader (Bio-Rad, Mississauga, ON, Canada).

Dark-Field Imaging and Hyperspectral Analysis. Dark-field imaging $(100 \times)$ of microglia cells was done using an Olympus BX-51 microscope and $100 \mathrm{~W}$ quartz halogen light source on a CytoViva microscope and software. Spectral data were captured with a CytoViva spectrophotometer and integrated CCD camera. Each spectrum shown represents a single pixel imaged with a $100 \times$ objective and approximately $64 \mathrm{~nm}$ in size. Spectral analysis was performed with the CytoViva Hyperspectral analysis software program.

Two-Photon Luminescence (TPL) Imaging. Two-photon imaging was performed on hippocampal neurons (day 21 in vitro). Images were acquired with a Zeiss LSM 510 upright microscope. An argon laser ( $488 \mathrm{~nm}, 0.525 \%$ max intensity) in combination with a BP 500-550 IR filter were used to image MitoTracker Green $\mathrm{FM}$, a HeNe laser ( $543 \mathrm{~nm}, 2 \%$ max intensity) in combination with a LP 560 filter was used to image LysoTracker Red DND-99, and a two-photon Ti:sapphire laser (set at $750 \mathrm{~nm} ; 5.0 \%$ max intensity) in combination with BP 390-465 IR filter was used to image GNPs. A Plan-Achromat vis-IR $63 \times$ NA 1.0 objective was used for all samples. No background fluorescence of cells was detected under the settings used. Images were acquired at a resolution of $1024 \times 1024$. Images were analyzed using the Zeiss Confocal LSM Image browser, in combination with ImageJ.

Inductively Coupled Plasma Absorption Emission Spectroscopy (ICP-AES). GNP-treated cells were trypsinized, pelleted, washed in PBS, and resuspended in water, and then they were sonicated at $15 \mathrm{~W}$. Nitric acid $\left(\mathrm{HNO}_{3}\right)$ was added to a final concentration of $5 \%$ prior to analysis by ICP-AES. ICP-AES data were acquired by a Jobin Yvon/Horiba JY200 instrument, using ICP sofware ICP Analyst v5.2. The gold ray wavelength was at $267.595 \mathrm{~nm}$.

Transgenic Animals and Genotyping. All experimental procedures with transgenic mice were approved by the Laval University animal care ethics committee and were in accordance with The Guide to the Care and Use of Experimental Animals of the Canadian Council on Animal Care. The transgenic TLR2-luc/gfp mice (in C57/Bl6 genetic background) were recently generated and genotyped in our laboratory employing the following primers for PCR: $5^{\prime}$ -

gcggactgttactgagctgcgt- and $5^{\prime}$-gaagcaatgctgtcaccttccc. ${ }^{51}$ The PCR conditions were as follows: $95^{\circ} \mathrm{C}, 15 \mathrm{~min}, 30$ cycles $\left(94{ }^{\circ} \mathrm{C}, 30 \mathrm{~s} ; 65^{\circ} \mathrm{C}, 30 \mathrm{~s} ; 72{ }^{\circ} \mathrm{C}, 1 \mathrm{~min} ; 72{ }^{\circ} \mathrm{C}, 7 \mathrm{~min}\right.$ ).

\section{Intranasal Administration of Gold Nanoparticles and In Vivo}

Bioluminescence Imaging. After anesthesia, the transgenic mice $(n=4)$ received intranasally (left nostril) $5 \mu \mathrm{L}$ of gold nanoparticles or PEGylated QD705 (Invitrogen) (each normalized to a concentration of $10^{9}$ particles $\mathrm{mL}^{-1}$ ) or the equal volume of sterile $0.9 \%$ saline solution ( $5 \mu \mathrm{L}$ ). QDs were used as a control for PEGylated nanoparticles and imaging. After intranasal delivery, the animals were then longitudinally imaged using IVIS 200 Imaging System (Xenogen, Alameda, CA). Prior to the imaging ses- 


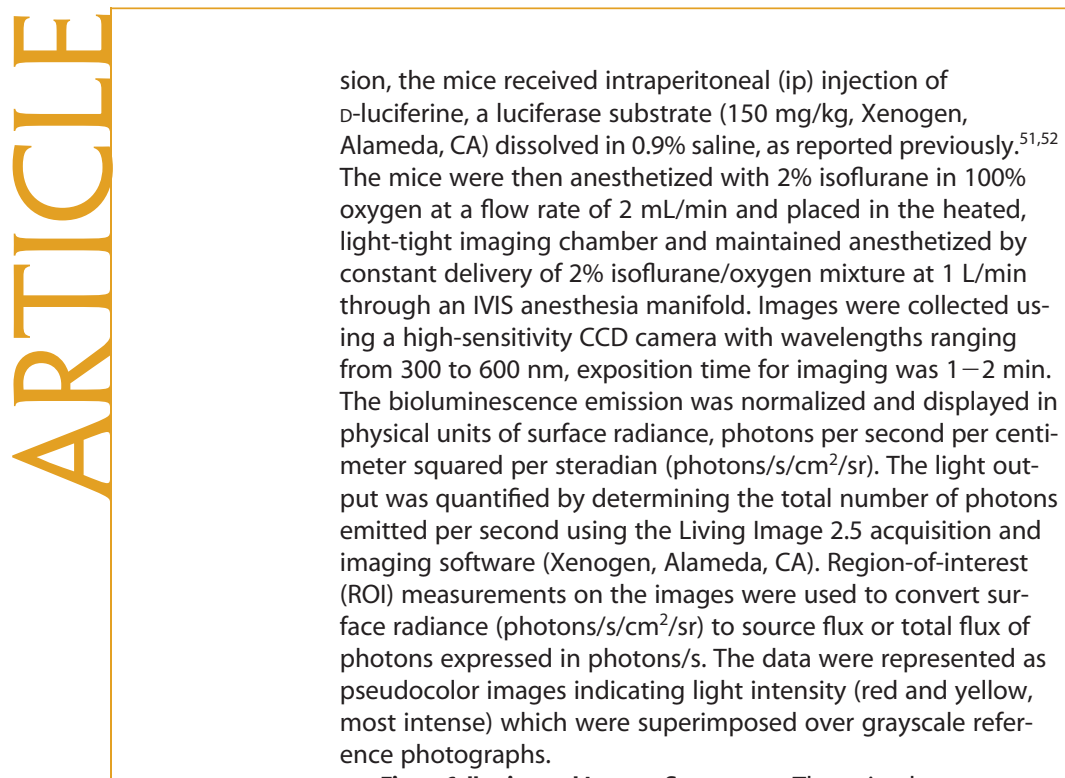

Tissue Collection and Immunofluorescence. The animals were anesthetized one week after gold nanoparticle or QD705 administration via an ip injection of chloral hydrate $(10 \mathrm{mg} / \mathrm{mL})$ and transcardially perfused with PBS followed by a $4 \%$ paraformaldehyde (PFA) solution at $\mathrm{pH}$ 7.4. Tissue sample were then postfixed overnight in 4\% PFA and then cryopreserved in phosphate-buffered $30 \%$ sucrose. Brains were embedded into Tissue-Tek (OCT compound, Sakura, USA), kept at $-20^{\circ} \mathrm{C}$ overnight, cut into coronal section with a Cryostat ( $35 \mu \mathrm{m}$ thick), and stored at $-20^{\circ} \mathrm{C}$. Immunofluorescence was carried out according to the procedures described previously. ${ }^{51}$ Briefly, $200 \mu \mathrm{m}$ sections were incubated overnight at room temperature with primary antibodies, 1:750 rabbit polyclonal anti-lba1 (Wako), washed in PBS, and incubated in corresponding fluorescent goat secondary antiserum (1:1000) (Invitrogen).

No Production. Nitric oxide (NO) release from N9 cells was measured using the Griess Reagent ( $1 \%$ sulphanilamide, $0.1 \% \mathrm{~N}-(1-$ naphthyl)ethylenediamine dihydrochloride, $5 \%$ phosphoric acid). After treatment, $50 \mu \mathrm{L}$ of the supernatant from each well was mixed with $50 \mu \mathrm{L}$ of Griess reagent in a clear bottom 96-well plate and incubated at room temperature for $15 \mathrm{~min}$. Absorbance at $540 \mathrm{~nm}$ for each sample was measured in triplicate using the microplate reader.

Western Blotting for Toll-like Receptor 2 (TLR-2). Following treatment, cells were trypsinized, pelleted, resuspended in lysis buffer, sonicated briefly, and centrifuged and supernatants collected. Of total cell extracts, $25 \mu \mathrm{g}$ was loaded onto a $10 \%$ gradient sodium dodecyl sulfate-polyacrylamide gel electrophoresis (SDS-PAGE) gel and transferred to a nitrocellulose membrane. Membranes were washed with $0.1 \%$ Tween-20 + TBS and blocked with $5 \%$ milk $+0.5 \%$ Tween-20 + TBS for $1 \mathrm{~h}$ at room temperature and incubated with goat anti-TLR-2 (R\&D Systems) diluted 1:500 in blocking solution overnight at $4{ }^{\circ} \mathrm{C}$. After five washes with $0.1 \%$ Tween-20 + TBS, the membranes were incubated with the HRP-conjugated anti-goat (Bio-Rad) diluted $1: 3000$ in $5 \%$ milk $+0.5 \%$ Tween-20 + TBS for $1 \mathrm{~h}$ at room temperature. After five washes with $0.1 \%$ Tween-20 + TBS, HRP substrate was added and incubated for $5 \mathrm{~min}$, following which the membranes were exposed to film,

ELISA Assay for Granulocyte Macrophage Colony-Stimulating Factor (GMCSF) and Interleukin 1 alpha (IL-1 $\alpha$ ). The cytokine secretion from microglia in the absence or presence of gold nanoparticles was analyzed by ELISA assay (SABiosciences). The supernatants of stimulated cells were collected after $6 \mathrm{~h}$ treatment at $37{ }^{\circ} \mathrm{C}$ and analyzed for cytokine secretion using commercially available cytokine ELISA kits: Multi-Analyte ELISArray for mouse inflammatory cytokines (interleukins $1 \alpha, 1 \beta, 2,6,8,10,12,17 \alpha$, tumor necrosis factor $\alpha$ (TNF $\alpha)$, granulocyte macrophage colonystimulating factor (GM-CSF), interferon $\gamma$ (IFN- $\gamma$ ), and macrophage colony-stimulating (M-CSF)) and single analyte ELISArray kits for IL- $1 \alpha$ and GM-CSF. Assays were conducted according to the manufacturer's protocol.
Statistical Analysis. All data were expressed as mean \pm SEM and analyzed by one-way ANOVA, as indicated. All values were obtained from at least three independent experiments. When a significant effect was obtained with one-way ANOVA, Dunnett's test was used to compare all values to the control. Alternatively, student's $t$-test was used to analyze significant differences between two group means.

Acknowledgment. The authors acknowledge Dr. Paul De Koninck for providing material and assistance for two-photon luminescence imaging in primary hippocampal neuronal cultures, the assistance of CytoViva, Inc. (Auburn, AL) in carrying out imaging and hyperspectral analysis of gold nanoparticle-treated microglia cells using CytoViva Microscope and Hyperspectral Imaging System, and Jacynthe Laliberte for technical assistance with two-photon luminescence imaging in microglia. S.B. is supported by a Doctoral Award through the Alzheimer Society of Canada. This work was supported in part by the Natural Sciences and Engineering Research Council of Canada under its strategic research program and the Canadian Institutes of Health Research.

Supporting Information Available: Dark-field images of internalized gold nanoparticles (GNPs) and two-photon luminescence images of PEG-coated GNPs in microglia. This material is available free of charge via the Internet at http://pubs.acs.org.

\section{REFERENCES AND NOTES}

1. Wang, H. F.; Huff, T. B.; Zweifel, D. A.; He, W.; Low, P. S.; Wei, A.; Cheng, J. X. In vitro and in vivo two-photon luminescence imaging of single gold nanorods. Proc. Natl. Acad. Sci. U.S.A. 2005, 102, 15752-15756.

2. Novo, C.; Funston, A. M.; Mulvaney, P. Direct observation of chemical reactions on single gold nanocrystals using surface plasmon spectroscopy. Nat. Nanotechnol. 2008, 3, 598-602.

3. Oh, E.; Hong, M. Y.; Lee, D.; Nam, S. H.; Yoon, H. C.; Kim, H. S. Inhibition assay of biomolecules based on fluorescence resonance energy transfer (FRET) between quantum dots and gold nanoparticles. J. Am. Chem. Soc. 2005, 127, 3270-3271.

4. Hutter, E.; Pileni, M. P. Detection of DNA hybridization by gold nanoparticle enhanced transmission surface plasmon resonance spectroscopy. J. Phys. Chem. B 2003, 107, 6497-6499.

5. Kim, C.; Ghosh, P.; Rotello, V. M. Multimodal drug delivery using gold nanoparticles. Nanoscale 2009, 1, 61-67.

6. Wijaya, A.; Schaffer, S. B.; Pallares, I. G.; Hamad-Schifferli, K. Selective release of multiple DNA oligonucleotides from gold nanorods. ACS Nano 2009, 3, 80-86.

7. Nam, J.; Won, N.; Jin, H.; Chung, H.; Kim, S. pH-Induced aggregation of gold nanoparticles for photothermal cancer therapy. J. Am. Chem. Soc. 2009, 131, 13639-13645.

8. Hutter, E.; Fendler, J. H. Exploitation of localized surface plasmon resonance. Adv. Mater. 2004, 16, 1685-1706.

9. Loo, C.; Lin, A.; Hirsch, L.; Lee, M. H.; Barton, J.; Halas, N.; West, J.; Drezek, R. Nanoshell-enabled photonics-based imaging and therapy of cancer. Technol. Cancer Res. Treat. 2004, 3, 33-40.

10. Yguerabide, J.; Yguerabide, E. E. Resonance light scattering particles as ultrasensitive labels for detection of analytes in a wide range of applications. J. Cell. Biochem. 2001, 84, 71-81.

11. El-Sayed, I. H.; Huang, X. H.; El-Sayed, M. A. Surface plasmon resonance scattering and absorption of antiEGFR antibody conjugated gold nanoparticles in cancer diagnostics: Applications in oral cancer. Nano Lett. 2005, 5, 829-834.

12. Imura, K.; Nagahara, T.; Okamoto, H. Plasmon mode imaging of single gold nanorods. J. Am. Chem. Soc. 2004, 126, 12730-12731.

13. Nativo, P.; Prior, I. A.; Brust, M. Uptake and intracellular fate of surface-modified gold nanoparticles. ACS Nano 2008, 2, 1639-1644. 
14. Hayat, M. A. Colloidal Gold. Principles, Methods and Applications; Academic Press, Inc.: San Diego, CA, 1989.

15. Jain, P. K.; Huang, X.; El-Sayed, I. H.; El-Sayed, M. A. Noble metals on the nanoscale: optical and photothermal properties and some applications in imaging, sensing, biology, and medicine. Acc. Chem. Res. 2008, 41, 1578-1586.

16. Sau, T. K.; Murphy, C. J. Seeded high yield synthesis of short Au nanorods in aqueous solution. Langmuir 2004, 20, 6414-6420.

17. Nikoobakht, B.; El-Sayed, M. A. Preparation and growth mechanism of gold nanorods (NRs) using seed-mediated growth method. Chem. Mater. 2003, 15, 1957-1962.

18. Bakr, O. M.; Wunsch, B. H.; Stellacci, F. High-yield synthesis of multi-branched urchin-like gold nanoparticles. Chem. Mater. 2006, 18, 3297-3301.

19. Lu, L. H.; Ai, K.; Ozaki, Y. Environmentally friendly synthesis of highly monodisperse biocompatible gold nanoparticles with urchin-like shape. Langmuir 2008, 24, 1058-1063.

20. Yu, K. F.; Kelly, K. L.; Sakai, N.; Tatsuma, T. Morphologies and surface plasmon resonance properties of monodisperse bumpy gold nanoparticles. Langmuir $\mathbf{2 0 0 8}$, 24, 5849-5854

21. Millstone, J. E.; Metraux, G. S.; Mirkin, C. A. Controlling the edge length of gold nanoprisms via a seed-mediated approach. Adv. Funct. Mater. 2006, 16, 1209-1214.

22. Lu, X. M.; Yavuz, M. S.; Tuan, H. Y.; Korgel, B. A.; Xia, Y. N. Ultrathin gold nanowires can be obtained by reducing polymeric strands of oleylamine-AuCl complexes formed via aurophilic interaction. J. Am. Chem. Soc. 2008, 130, 8900-8901.

23. Shen, Z. R.; Miyabayashi, K.; Higashimoto, M.; Shimoda, T.; Miyake, M. Single-crystalline gold nanodisks prepared by the shape transformation under UV irradiation from nanoparticles protected with discotic liquid crystalline ligands. Chem. Lett. 2008, 37, 1276-1277.

24. Khoury, C. G.; Vo-Dinh, T. Gold nanostars for surfaceenhanced raman scattering: synthesis, characterization and optimization. J. Phys. Chem. C 2008, 112, 18849-18859.

25. Kumar, P. S.; Pastoriza-Santos, I.; Rodriguez-Gonzalez, B.; Garcia de Abajo, F. J.; Liz-Marzan, L. M. High-yield synthesis and optical response of gold nanostars. Nanotechnology 2008, 19, 015606.

26. Yuan, H.; Ma, W. H.; Chen, C. C.; Zhao, J. C.; Liu, J. W.; Zhu H. Y.; Gao, X. P. Shape and SPR evolution of thorny gold nanoparticles promoted by silver ions. Chem. Mater. 2007, 19, 1592-1600.

27. Alkilany, A., M.; Pratik, K. N.; Cole, R. H.; Timothy, J. S.; Catherine, J. M.; Michael, D. W. Cellular uptake and cytotoxicity of gold nanorods: molecular origin of cytotoxicity and surface effects. Small 2009, 5, 701-708.

28. Chithrani, B. D.; Chan, W. C. W. Elucidating the mechanism of cellular uptake and removal of protein-coated gold nanoparticles of different sizes and shapes. Nano Lett. 2007, 7, 1542-1550.

29. Chithrani, B. D.; Ghazani, A. A.; Chan, W. C. W. Determining the size and shape dependence of gold nanoparticle uptake into mammalian cells. Nano Lett. 2006, 6, 662-668.

30. De Jong, W. H.; Hagens, W. I.; Krystek, P.; Burger, M. C.; Sips, A. J. A. M.; Geertsma, R. E. Particle size-dependent organ distribution of gold nanoparticles after intravenous administration. Biomaterials 2008, 29, 1912-1919.

31. Semmler-Behnke, M.; Kreyling, W. G.; Lipka, J.; Fertsch, S.; Wenk, A.; Takenaka, S.; Schmid, G.; Brandau, W. Biodistribution of 1.4- and 18-nm gold particles in rats. Small 2008, 4, 2108-2111.

32. Pan, Y.; Neuss, S.; Leifert, A.; Fischler, M.; Wen, F.; Simon, U.; Schmid, G.; Brandau, W.; Jahnen-Dechent, W. Sizedependent cytotoxicity of gold nanoparticles. Small 2007, 3, 1941-1949.

33. Hung-Jen, Y.; Shan-hui, H.; Ching-Lin, T. Cytotoxicity and immunological response of gold and silver nanoparticles of different sizes. Small 2009, 5, 1553-1561.
34. Au, L.; Zhang, Q.; Cobley, C. M.; Gidding, M.; Schwartz, A. G.; Chen, J.; Xia, Y. Quantifying the cellular uptake of antibody-conjugated Au nanocages by two-photon microscopy and inductively coupled plasma mass spectrometry. ACS Nano. 2009, 4, 35-42.

35. Huff, T. B.; Hansen, M. N.; Zhao, Y.; Cheng, J. X.; Wei, A. Controlling the cellular uptake of gold nanorods. Langmuir 2007, 23, 1596-1599.

36. Gratton, S. E.; Ropp, P. A.; Pohlhaus, P. D.; Luft, J. C.; Madden, V. J.; Napier, M. E.; DeSimone, J. M. The effect of particle design on cellular internalization pathways. Proc. Natl. Acad. Sci. U.S.A. 2008, 105, 11613-11618.

37. Mitragotri, S.; Lahann, J. Physical approaches to biomaterial design. Nat. Mater. 2009, 8, 15-23.

38. Malugin, A.; Ghandehari, H. Cellular uptake and toxicity of gold nanoparticles in prostate cancer cells: a comparative study of rods and spheres. J. Appl. Toxicol. 2009, early view.

39. Hanisch, U. K.; Kettenmann, H. Microglia: active sensor and versatile effector cells in the normal and pathologic brain. Nat. Neurosci. 2007, 10, 1387-1394.

40. Takeda, K.; Akira, S. Toll-like receptors in innate immunity. Int. Immunol. 2005, 17, 1-14.

41. Block, M. L.; Zecca, L.; Hong, J. S. Microglia-mediated neurotoxicity: uncovering the molecular mechanisms. Nat. Rev. Neurosci. 2007, 8, 57-69.

42. Niidome, T.; Yamagata, M.; Okamoto, Y.; Akiyama, Y.; Takahashi, H.; Kawano, T.; Katayama, Y.; Niidome, Y. PEGmodified gold nanorods with a stealth character for in vivo applications. J. Controlled Release 2006, 114, 343-347.

43. Righi, M.; Mori, L.; De Libero, G.; Sironi, M.; Biondi, A.; Mantovani, A.; Donini, S. D.; Ricciardi-Castagnoli, P. Monokine production by microglial cell clones. Eur. J. Immunol. 1989, 19, 1443-1448.

44. Verma, A.; Stellacci, F. Effect of surface properties on nanoparticle-cell interactions. Small 2009, 6, 12-21.

45. Connor, E. E.; Mwamuka, J.; Gole, A.; Murphy, C. J.; Wyatt, M. D. Gold nanoparticles are taken up by human cells but do not cause acute cytotoxicity. Small 2005, 1, 325-327.

46. Hauck, T. S.; Ghazani, A. A.; Chan, W. C. W. Assessing the effect of surface chemistry on gold nanorod uptake, toxicity, and gene expression in mammalian cells. Small 2008, 4, 153-159.

47. Takahashi, H.; Niidome, Y.; Niidome, T.; Kaneko, K.; Kawasaki, H.; Yamada, S. Modification of gold nanorods using phospatidylcholine to reduce cytotoxicity. Langmuir 2006, 22, 2-5.

48. Leonov, A. P.; Zheng, J. W.; Clogston, J. D.; Stern, S. T.; Patri, A. K.; Wei, A. Detoxification of gold nanorods by treatment with polystyrenesulfonate. ACS Nano 2008, 2, 2481-2488.

49. Schafer, V.; von Briesen, H.; Andreesen, R.; Steffan, A. M.; Royer, C.; Troster, S.; Kreuter, J.; Rubsamen-Waigmann, H. Phagocytosis of nanoparticles by human immunodeficiency virus (HIV)-infected macrophages: a possibility for antiviral drug targeting. Pharm. Res. 1992, 9, 541-546.

50. Kriz, J.; Lalancette-Hébert, M. Inflammation, plasticity and real-time imaging after cerebral ischemia. Acta Neuropathol. 2009, 117, 497-509.

51. Lalancette-Hebert, M.; Phaneuf, D.; Soucy, G.; Weng, Y. C.; $\mathrm{Kriz}$, J. Live imaging of toll-like receptor 2 response in cerebral ischaemia reveals a role of olfactory bulb microglia as modulators of inflammation. Brain 2009, 132, 940-954.

52. Maysinger, D.; Behrendt, M.; Lalancette-Hebert, M.; Kriz, J. Real-time imaging of astrocyte response to quantum dots: in vivo screening model system for biocompatibility of nanoparticles. Nano Lett. 2007, 7, 2513-2520.

53. Hernandez, J.; Solla-Gullon, J.; Herrero, E.; Aldaz, A.; Feliu, J. M. Electrochemistry of shape-controlled catalysts: oxygen reduction reaction on cubic gold nanoparticles. $J$. Phys. Chem. C 2007, 111, 14078-14083. 
54. Jia, H. Y.; Liu, Y.; Zhang, X. J.; Han, L.; Du, L. B.; Tian, Q.; Xu, Y. C. Potential oxidative stress of gold nanoparticles by induced-NO releasing in serum. J. Am. Chem. Soc. 2008, $131,40-41$.

55. Chen, K.; Iribarren, P.; Hu, J.; Chen, J.; Gong, W.; Cho, E. H.; Lockett, S.; Dunlop, N. M.; Wang, J. M. Activation of toll-like receptor 2 on microglia promotes cell uptake of Alzheimer disease-associated amyloid beta peptide. J. Biol. Chem. 2006, 281, 3651-3659.

56. Syed, M. M.; Phulwani, N. K.; Kielian, T. Tumor necrosis factor-alpha (TNF- $\alpha$ ) regulates toll-like receptor 2 (TLR2) expression in microglia. J. Neurochem. 2007, 103, 1461-1471.

57. Lee, M. S.; Kim, Y. J. Signaling pathways downstream of pattern-recognition receptors and their cross talk. Annu. Rev. Biochem. 2007, 76, 447-480.

58. Sanjuan, M. A.; Dillon, C. P.; Tait, S. W. G.; Moshiach, S.; Dorsey, F.; Connell, S.; Komatsu, M.; Tanaka, K.; Cleveland, J. L.; Withoff, S.; Green, D. R. Toll-like receptor signalling in macrophages links the autophagy pathway to phagocytosis. Nature 2007, 450, 1253-1257.

59. Mrabet-Dahbi, S.; Metz, M.; Dudeck, A.; Zuberbier, T.; Maurer, M. Murine mast cells secrete a unique profile of cytokines and prostaglandins in response to distinct TLR2 ligands. Exp. Dermatol. 2009, 18, 437-444.

60. Choi, A. O.; Brown, S. E.; Szyf, M.; Maysinger, D. Quantum dot-induced epigenetic and genotoxic changes in human breast cancer cells. J. Mol. Med. 2008, 86, 291-302.

61. Wang, J.; Li, Y. F.; Huang, C. Z.; Wu, T. Rapid and selective detection of cysteine based on its induced aggregates of cetyltrimethylammonium bromide capped gold nanoparticles. Anal. Chim. Acta 2008, 626, 37-43.

62. Sau, T. K.; Murphy, C. J. Seeded high yield synthesis of short Au nanorods in aqueous solution. Langmuir 2004, 20, 6414-6420.

63. Hongwei, L.; Hafner, J. H. Gold nanorod bioconjugates. Chem. Mater. 2005, 17, 4636-4641.

64. Pierrat, S.; Zins, I.; Breivogel, A.; Sonnichsen, C. Selfassembly of small gold colloids with functionalized gold nanorods. Nano Lett. 2007, 7, 259-263.

65. Mosmann, T. Rapid colorimetric assay for cellular growth and survival: application to proliferation and cytotoxicity assays. J. Immunol. Methods 1983, 65, 55-63. 